\title{
Resource Letter OSE-1: Observing Solar Eclipses
}

Jay M. PasachoffAndrew Fraknoi

Citation: American Journal of Physics 85, 485 (2017); doi: 10.1119/1.4985062

View online: http://dx.doi.org/10.1119/1.4985062

View Table of Contents: http://aapt.scitation.org/toc/ajp/85/7

Published by the American Association of Physics Teachers

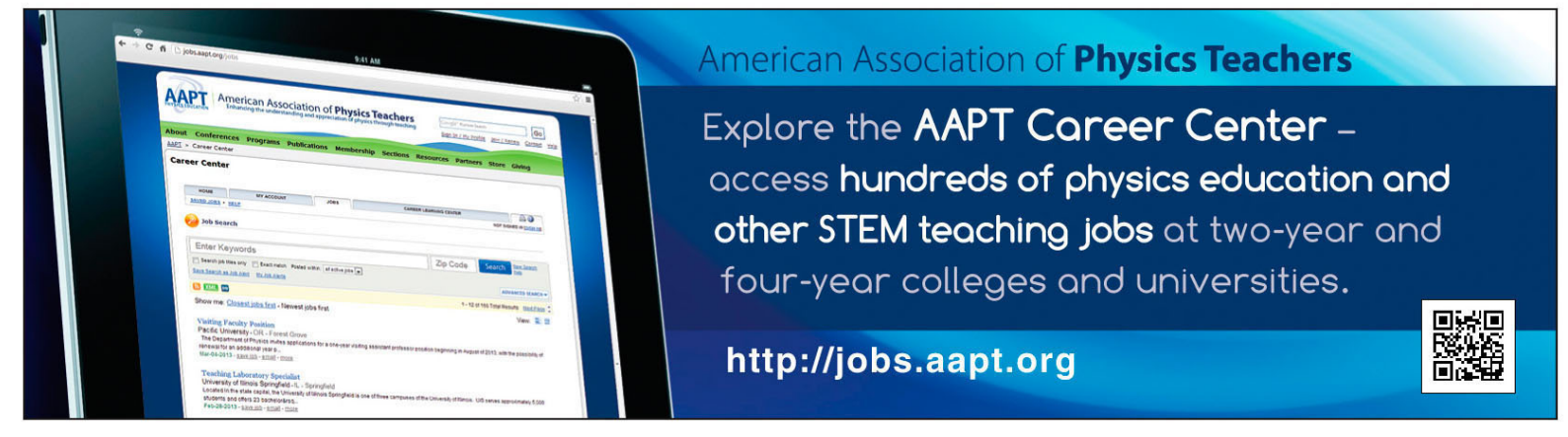




\title{
RESOURCE LETTER
}

Resource Letters are guides for college and university physicists, astronomers, and other scientists to literature, websites, and other teaching aids. Each Resource Letter focuses on a particular topic and is intended to help teachers improve course content in a specific field of physics or to introduce nonspecialists to this field. The Resource Letters Editorial Board meets annually to choose topics for which Resource Letters will be commissioned during the ensuing year. Items in the Resource Letter below are labeled with the letter E to indicate elementary level or material of general interest to persons seeking to become informed in the field, the letter I to indicate intermediate level or somewhat specialized material, or the letter A to indicate advanced or specialized material. No Resource Letter is meant to be exhaustive and complete; in time there may be more than one Resource Letter on a given subject. A complete list by field of all Resource Letters published to date is at the website <http://ajp.dickinson.edu/ Readers/resLetters.html>. Suggestions for future Resource Letters, including those of high pedagogical value, are welcome and should be sent to Professor Mario Belloni, Editor, AJP Resource Letters, Davidson College, Department of Physics, Box 6910, Davidson, NC 28035; e-mail: mabelloni@davidson.edu.

\section{Resource Letter OSE-1: Observing Solar Eclipses}

\author{
Jay M. Pasachoff \\ Hopkins Observatory, Williams College, Williamstown, Massachusetts 01267 and Division of Geological \\ and Planetary Sciences, Caltech, Pasadena, California 91125
}

Andrew Fraknoi

Foothill College, Los Altos Hills, California 94022

(Received 8 April 2017; accepted 22 May 2017)

\begin{abstract}
This Resource Letter provides a guide to the available literature, listing selected books, articles, and online resources about scientific, cultural, and practical issues related to observing solar eclipses. It is timely, given that a total solar eclipse will cross the continental United States on August 21, 2017. The next total solar eclipse path crossing the U.S. and Canada will be on April 8, 2024. In 2023, the path of annularity of an annular eclipse will cross Mexico, the United States, and Canada, with partial phases visible throughout those countries. (C) 2017 American Association of Physics Teachers.

[http://dx.doi.org/10.1119/1.4985062]
\end{abstract}

\section{INTRODUCTION}

A 60- to 71-mile-wide band of totality will cross the Continental United States on August 21, 2017, taking 90 min to span the continent with totality on the centerline ranging from about $2 \mathrm{~min}$ in Oregon to a maximum of $2 \mathrm{~min} 40 \mathrm{~s}$ in Illinois and Kentucky. The path of totality will pass through narrow paths in 12 states-Oregon, Idaho, Wyoming, Nebraska, Kansas, Missouri, Illinois, Kentucky, Tennessee, North Carolina, Georgia, and South Carolina-and clip small corners of Montana and Iowa. Since the 1918 total solar eclipse, the previous eclipse with totality that crossed the United States from coast to coast went through Bermuda, this is the first eclipse since the founding of the United States with totality entirely in the one country (Fig. 1).

The rest of the United States will see a partial eclipse, including Alaska and Hawaii; from all of Canada except the northernmost portion; from all of Mexico and Central America; and from northern South America; as well as from westernmost Africa and westernmost Europe near sunset. The solar corona is about a million times fainter than the solar photosphere, the everyday solar surface. This means that even if only $1 \%$ of the photosphere remains uncovered by the Moon's silhouette during a solar eclipse (a so-called $99 \%$ eclipse), the sky is still 10,000 times brighter than it is during totality. In other words, even when the Moon covers $99 \%$ of the solar diameter, the sky remains blue and the photosphere is too bright to allow the solar corona to be seen.

Whenever part of the photosphere, the everyday solar disk, is visible in a clear sky, it is unsafe to stare at it directly (or to look however briefly through any optical device such as a telescope or binoculars). Accordingly, it is important for eclipse-watchers to have suitable solar filters to look through at the solar crescent, or to use methods of projection such as "pinhole cameras." Images are much clearer with the new generation of "Mylar" or related filters, available very inexpensively, than with pinhole projection. For those using filter material with telescopes or binoculars, sage advice is to use the filter material on the front, Sun-facing side of the optical device, lest the concentrated solar rays burn a hole in the material if used at the exit/eyepiece.

However, it is important to note that the solar corona itself, during the minutes or seconds of totality, is about the same brightness as the full moon and equally safe to look at. Those neglecting to take off the filters for totality will not be able to see anything of the subtle, but beautiful solar phenomena an eclipse reveals. In order, these exciting phenomena are, after the last solar crescent seen through filters is extinguished, Baily's beads (the photosphere shining through the valleys on the edge of the Moon), the diamond-ring effect (the last Baily's bead shining brightly), the reddish solar chromosphere, and then-for the duration of totalitythe solar corona, often described as pearly white. At the end of totality, the chromosphere, diamond ring, and Baily's beads appear in reverse order, and during the second diamond ring people must again begin to look only through proper filters (Figs. 2 and 4).

The eclipse of August 21, 2017 will be a major event across the United States and adjacent countries, with much publicity and excitement in the days leading up to it. If you 


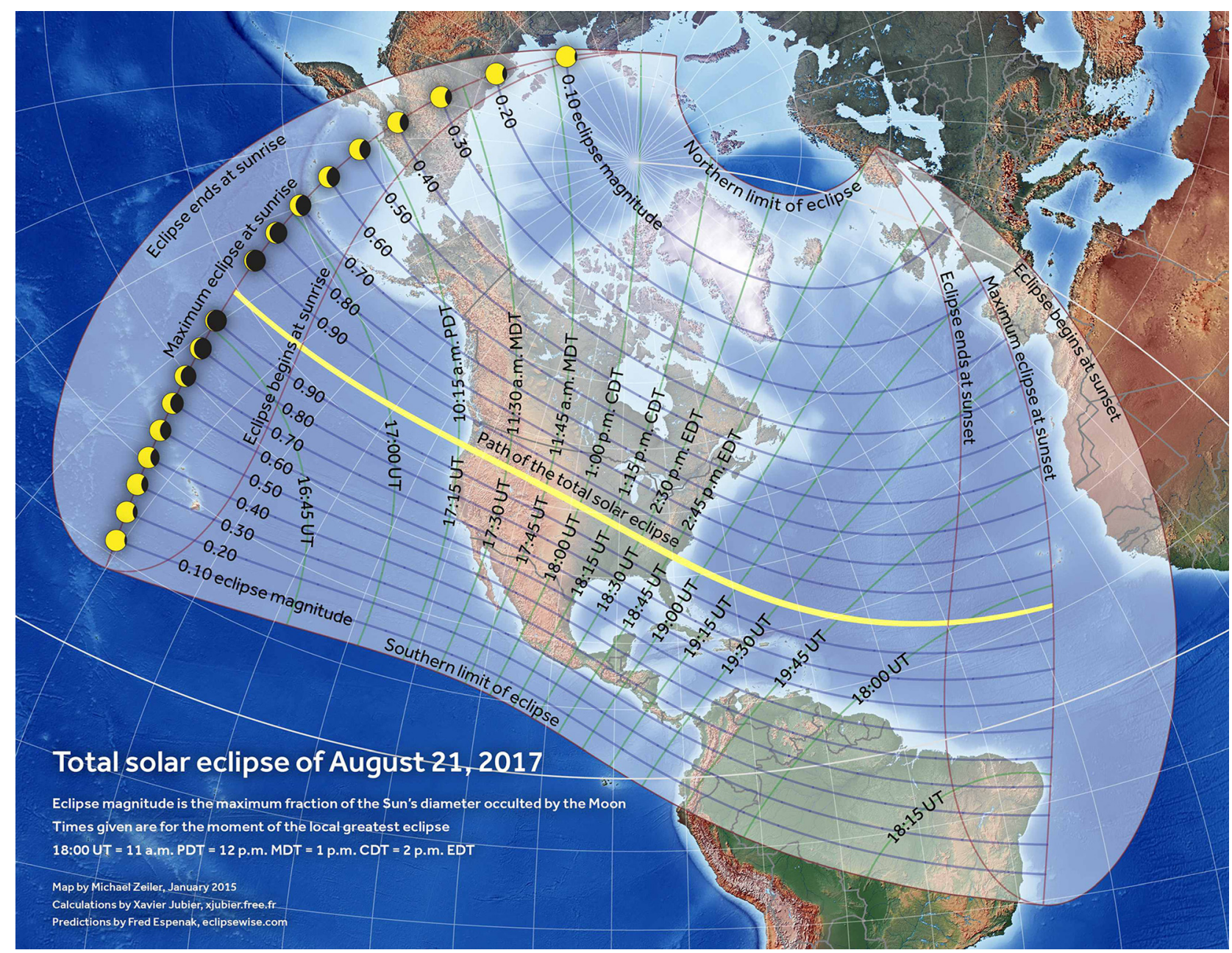

Fig. 1. The extent of the partial solar eclipse on August 21, 2017, with the path of totality delineated. (Courtesy of Michael Zeiler, http://GreatAmericanEclipse.com).

miss it, the next total solar eclipse path crossing the U.S. and Canada (from Texas through Maine) will be on April 8, 2024 (see Fig. 3). In 2023, the path of annularity of an annular eclipse will cross Mexico, the United States, and Canada, with partial phases throughout those countries. Partial phases

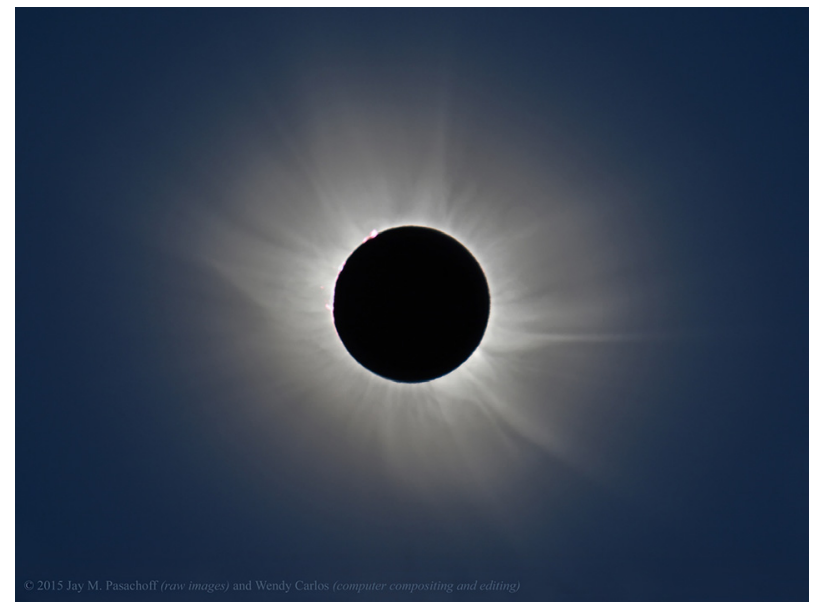

Fig. 2. The solar corona surrounds the reddish solar chromosphere and prominences and the dark silhouette of the Moon in this composite image from Jay Pasachoff's Williams College Eclipse Expedition to Svalbard in 2015. (Credit: Copyright 2015 Jay Pasachoff (raw images) and Wendy Carlos (computer compositing and editing)). will be visible in the eastern U.S. on June 10, 2021, from an annular eclipse in Canada.

\section{TRAVEL AND OBSERVING GUIDES FOR THE 2017 ECLIPSE}

Tens or hundreds of millions of people will be on the road, traveling on eclipse day or shortly before to get into the zone of totality. Communities within totality should plan to have adequate facilities to receive the onslaught, matching or exceeding hurricane-evacuation levels but in good weather and with months to plan.

\section{A. Short guides to the 2017 eclipse}

1. "See the Great American Eclipse of August 21, 2017," Michael Zeiler. http://greatamericaneclipse.com. Including two partial-eclipse glasses. Also available as an eBook.

2. "Get Eclipsed: The Complete Guide to the American Eclipse," Pat Espenak and Fred Espenak, http://astropixels.com/pubs/GetEclipsed.html. Includes a pair of partialeclipse glasses.

3. "Guide to the 2017 Eclipse," Andrew Fraknoi and Dennis Schatz, National Science Teachers Association. http:// www.nsta.org/publications/press/extras/files/solarscience/ SolarScienceInsert.pdf. An 8-page PDF guide to eclipse information, circumstances, and viewing. 


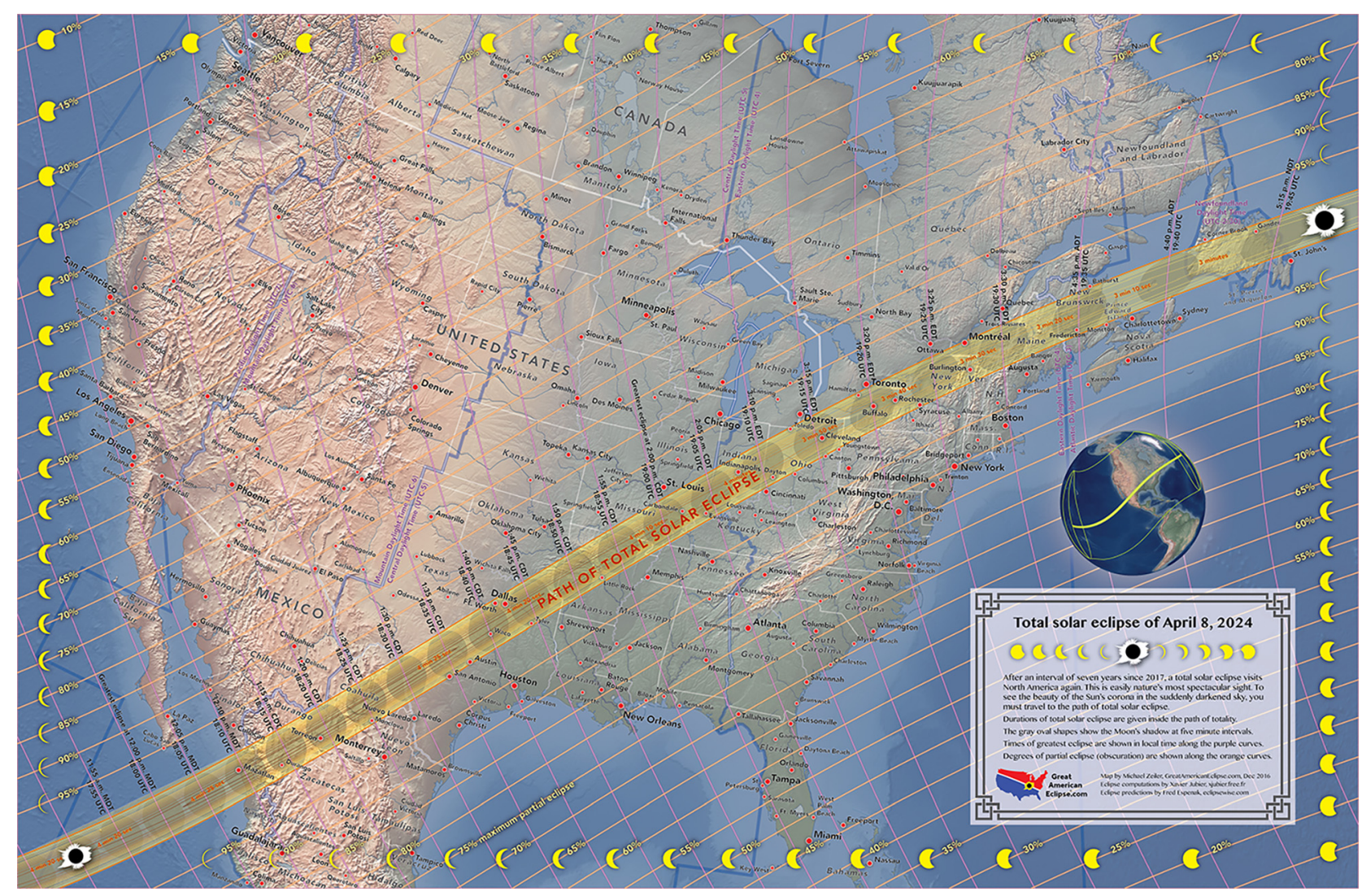

Fig. 3. The visibility of the April 8, 2024, total solar eclipse across Mexico, the United States, and Canada. Courtesy of Michael Zeiler, http://eclipse-maps.com).

4. "White Paper: Community Eclipse Planning," Kate Russo, available at: http://www.beingintheshadow.com/ books/white-paper-community-eclipse-planning/.

Guide for the planning of a total solar eclipse in your community.

\section{B. Detailed maps for the 2017 eclipse}

Printed and on-line materials can help pinpoint where viewers want to go. The projection of the near-round ellipse on the surface of the United States leaves the longest totality along the centerline, but with such substantial totality for twenty or so miles on either side of the centerline that almost all viewers would be satisfied. For dramatic effects, the beginning and the end of totality are most important, and extra seconds or a minute may well be less important than good logistics. Some experienced eclipse observers even choose to be just within the edge

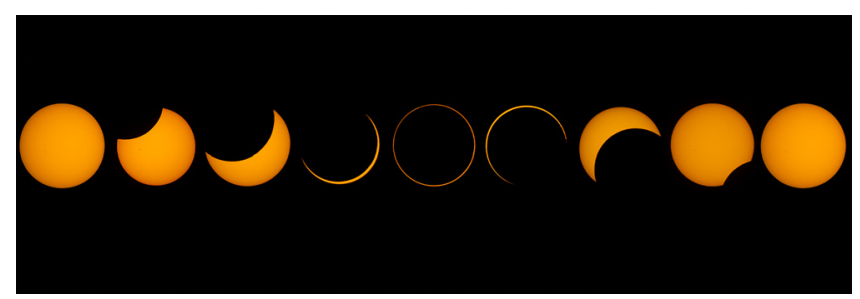

Fig. 4. A composite image from the series of partial and annular eclipse image taken by Jay Pasachoff in Patagonian Argentina on February 26, 2017, over a couple of hours. (Credit: Jay Pasachoff images, composited by Christian Lockwood, Williams College '20) of the path, which can be predicted accurately given $3 \mathrm{D}$ mapping of the Moon by American and Japanese spacecraft.

5. "Road Atlas for the Total Solar Eclipse of 2017," Fred Espenak (Astropixels Publishing, 2015). Available at: http://astropixels.com.

6. "GreatAmericanEclipse.com," Michael Zeiler's State by State maps of the Eclipse Path: https://www.greatamericaneclipse.com/ (see the menu of States).

7. "For the August 21, 2017, Total Eclipse in the United States," Xavier Jubier (2017). http://xjubier.free.fr/en/site_ pages/solar_eclipses/XSE_GoogleMap3.php?Ecl =+201708 $21 \& \mathrm{Acc}=2 \& \mathrm{Umb}=1 \& \mathrm{Lmt}=1 \& \mathrm{Mag}=1 \& \mathrm{Max}=1 \& \mathrm{Map}$ $=$ ROADMAP

Note that similar maps for future eclipses can be obtained by merely changing the "20170821" date, or by following links on M. Jubier's website.

\section{General Web resources}

The major websites about the eclipse listed here provide many links to other websites and sources of reliable information about the science and the logistics of this total solar eclipse.

8. Working Group on Solar Eclipses of the International Astronomical Union Website. http://eclipses.info.

9. "Eclipse Bulletin: Total Solar Eclipse of 2017 August 21," Fred Espenak and Jay Anderson (Astropixels Publishing, 2015). Available at: http://astropixels.com.

10. American Astronomical Society Website: http://eclipse. aas.org. Rich site with good information for the public and educators from the society for professional 
astronomers. Twitter handle, @AAS_Eclipse (https://twitter.com/aas_eclipse) and Facebook page (https://www.facebook.com/AASeclipse/).

Copyright-free eclipse images are available at: https:// eclipse.aas.org/resources/image-videos.

11. Great American Eclipse Website, Michael Zeiler, http:// GreatAmericanEclipse.com. Major website on the 2017 eclipse with many resources, excellent maps, and an App.

12. "EclipseWise.com: Predictions for Solar and Lunar Eclipses," Fred Espenak. Website (superseding the "NASA Eclipse Website") available at: http:// EclipseWise.com.

13. Jay Anderson's Website. http://eclipsophile.com. Weather and climate discussions and statistics.

14. Astronomical Society of the Pacific Guide to Eclipse Resources: https://www.astrosociety.org/education/2017solar-eclipse-information-resources/ Includes information and educational materials.

15. Xavier Jubier's Website. http://xjubier.free.fr/en/site_ pages/Solar_Eclipses.html. Website with solar eclipse maps such as Ref. 7.

16. Bill Kramer's website. http://eclipse-chasers.com. Includes a $\log$ of eclipses seen by eclipse-chasers from all over the world, a section on solar-eclipse basics, a section on solar-eclipse safety, a set of Kramer's eclipserelevant cartoons. A good general site for novices and dedicated amateurs alike.

17. Jay Pasachoff's Website. http://totalsolareclipse.org. Information, including sets of photos, about past and current eclipses observed from Williams College Expeditions, with many contemporaneous links.

18. Dan McGlaun's Website. http://eclipse2017.org/eclipse 2017_main.htm. A good general site for amateurs.

19. NASA's 2017 Eclipse Website. http://eclipse2017.nasa. gov. Extensive site with good links to science and education programs. A list of their approved viewing sites is at https:// eclipse2017.nasa.gov/nasa-official-viewing-locations.

20. Front Page Science: The Eclipse: http://www.fpsci.com/ start.html. Website from Astronomy Magazine editor Michael Bakich, full of activities, guides, and observing hints.

21. "2017 August 21 Total Solar Eclipse," U.S. Naval Observatory. http://aa.usno.navy.mil/data/docs/Eclipse 2017.php. Website includes maps and calculators. In conjunction with Her Majesty's Nautical Almanac Office, USNO also has a general eclipse portal: http:// astro.ukho.gov.uk/eclbin/query_usno.cgi. See also the "2024 April 8 Total Solar Eclipse" at: http://aa.usno. navy.mil/data/docs/Eclipse2024.php.

\section{Resources about safe eclipse viewing}

During the period of totality of an eclipse, it is completely safe to look at the Sun directly without any filters, but before or after, or outside the path of totality, it is not safe to look at the Sun for more than a glance. The American Astronomical Society has prepared a one-page information sheet about safe observing. Filters-in the form of glasses, or single cards, or even yard-square or footsquare sheets of material for use with classes or familiesare inexpensive.

22. "Solar Eclipse Eye Safety," B. Ralph Chou, American Astronomical Society Website. Available at: https:// eclipse.aas.org/eye-safety. Information on safely viewing eclipses and other useful information.

23. "How to View a Solar Eclipse Safely," American Astronomical Society. One-page summary on eye safety during eclipses: https://eclipse.aas.org/sites/eclipse.aas. org/files/AAS-Solar-Eclipse-Safety-v170210.pdf

The next four resources are suppliers of partial-eclipse glasses, also usable outside of eclipse. For validating their safety, these eclipse glasses should cite International Standards Org: ISO 12312-2.

24. "Solar Filters \& Viewers," AAS Website. https://eclipse.aas.org/resources/solar-filters. Summary of manufacturers and dealers of solar filters and viewers.

25. Thousand Oaks Optical, http://thousandoaksoptical.com.

26. Rainbow Symphony, https://www.rainbowsymphony. com/eclipse-glasses.

27. American Paper Optics, http://www.eclipseglasses.com.

The following five resources are websites with information for eclipse photography.

28. Eclipse Chaser Website. https://www.eclipse-chasers. com/photo/Photo.shtml.

29. Mr. Eclipse.com Website. http://www.mreclipse.com/ SEphoto/SEphoto.html.

30. Eclipse2017.org Website. http://www.eclipse2017.org/ 2017/photographing.htm.

31. American Astronomical Society Website. https://eclipse.aas.org/imaging-video/images-videos.

32. How to Photograph the Solar Eclipse: A Guide to Capturing the 2017 Total Eclipse of the Sun, Alan Dyer (AmazingSky.com, 2017). Book on eclipse photography available at: http://www.amazingsky.com/ eclipsebook.html.

\section{E. Materials for educators and librarians}

Educators at all levels have created freely available materials to prepare others for communicating details of the eclipse to students and the public. Examples below include materials from the American Astronomical Society and the National Science Teachers Association.

33. "Educational Materials \& Videos Website," American Astronomical Society. Available at: https://eclipse.aas.org/resources/educational-materials.

34. Solar Science: Exploring Sunspots, Seasons, Eclipses and More, Dennis Schatz and Andrew Fraknoi (National Science Teachers Association Press, 2016). A book of 45 hands-on activities for in or out of the classroom use by teachers, museum and nature center educators, librarians, etc. Includes a booklet on the 2017 eclipse and eclipse glasses. http://www.nsta.org/publications/press/extras/solarscience.aspx.

35. "Universe in the Classroom," Newsletter of the Astronomical Society of the Pacific. Fall 2016 Newsletter: Getting Ready for the All American Eclipse: An NGSS Storyline Approach to Classroom Instruction, by Brian Kruse: https://www.astrosociety.org/wp-content/ uploads/2016/10/uitc93.pdf

36. "Great American Eclipse of the Sun-August 21, 2017," Doug Duncan, Fiske Planetarium Website, University of Colorado. http://www.colorado.edu/ eclipse. With a link to a 7-min video on "Frequently Asked Questions" explaining the importance of the 
eclipse and how to watch it: https://www.youtube.com/ watch? $\mathrm{v}=\mathrm{yg} 5 \mathrm{jsz} 3 \mathrm{vh} 3 \mathrm{c}$

37. "Scientific and Outreach Opportunities Associated with the Upcoming Eclipse," Jay M. Pasachoff (Recorded January 27, 2017). Video press conference at the January 2017 American Physical Society Meeting. http://apswebcasting. com/webcast/archive/aps/jan2017/jan30-17-3.html

38. "Online Workshop: Tips for Planning Your August 21, 2017 Solar Eclipse Event," National Informal STEM Education Network Video (Recorded January 27, 2017). https://vimeo.com/201369511. This webinar provides information to help informal educators get ready for and do public outreach for the 2017 solar eclipse. Speakers were Ali Jackson, Andrew Fraknoi and Dennis Schatz.

39. "Eclipse Resource Center: Vetted Programming Materials for Libraries," STARNet Libraries Network: http://www. starnetlibraries.org/2017eclipse/eclipse-resource-center/. The Moore Foundation and Google are making 2 million eclipse glasses and a booklet of outreach ideas available free through public libraries. You can find full information at this website.

\section{F. Citizen science}

Members of the public have several ways they can contribute to scientific observations through "citizen-science" participation.

40. "Megamovie," A project headed by the Multiverse group at the Space Sciences Lab of the University of California at Berkeley, aided by Google, to collect images of totality from people across the country, with separate movies made (1) with DSLR imaging; and (2) with smartphones. An app is available to control the cameras. https://eclipsemega. movie or http://eclipsemegamovie.com.

41. "Citizen CATE Experiment," The CATE (Continental America Telescopic Eclipse) experiment aims to capture images of the inner solar corona using a network of $60+$ identical telescopes: http://eo.nso.edu/citizencatexs.

42. "Life Responds," California Academy of Science. Project to gather and merge reports from all along the eclipse path to see how living things react to the eclipse: https:// www.calacademy.org/citizen-science/solar-eclipse-2017.

\section{G. Children's books and magazines}

Several excellent sources for children of any age are available, preparing them and getting them excited about the coming eclipse.

\section{Children's non-fiction}

43. Total Eclipse or Bust!: A Family Road Trip, Patricia Totten Espenak (Astropixels Publishing, 2016).

44. When the Sun Goes Dark, Andrew Fraknoi and Dennis Schatz (National Science Teachers Association, 2017). An illustrated guide to eclipses for kids ages 9-14.

45. "What's Up with Eclipses?" Jay M. Pasachoff and Naomi Pasachoff, Consulting Editors, January 2017 issue of Dig into History vol. 19, no. 1 (Cricket Publishing). Available at: http://shop.cricketmedia.com/eclipse, 1-800-821-0115. A guide to eclipses for ages 9-14.

46. "When the Moon Hides the Sun," Jay M. Pasachoff, Odyssey, pages 36-39 (May/June 2011).
47. The Big Eclipse, Nancy Coffelt (Orbit Oregon, 2016). Children's book by illustrator and author Nancy Coffelt. Each book comes with a safe solar eclipse viewer. Ages $5-11$.

48. Looking Up!: The Science of Stargazing, Joe Rao (Simon Spotlight, 2017). Grades 2-4. Information on the solar system with a final chapter on solar and lunar eclipses.

49. Eclipse: Darkness in Daytime, Franklyn Branley, illustrated by Donald Crews (Trophy Press; Revised Edition, June 1988). Very elementary. Note that in one place it omits the 2017 eclipse and shows a map of only the 2024 event, though both are mentioned near the end.

50. Eclipses, The Night Sky and Other Amazing Sights in Space Series, Nick Hunter (Heinemann, 2013). A very nice book for young children with full-page photos of eclipses $7^{1} / 2^{\prime \prime} \times 8^{3} / 4^{\prime \prime}$ format), even including one of JMP with Donald Menzel and Fernando de Romaña at our eclipse site in Miahuatlán, Oaxaca, Mexico, for the 1970 eclipse. There is a serious error on p. 26, where it says that the eclipse will be on August 17, 2017, instead of August 21.

51. Go See the Eclipse: And Take a Kid with You, Chap Percival (Bee Ridge Press, 2015).

\section{Children's fiction}

52. Someone Is Eating the Sun, Ruth A. Sonneborn (Random House Pictureback, 1974). A book about eclipses for very young children.

53. Every Soul A Star, Wendy Mass (Little Brown, 2009). Middle-school novel.

54. Earth, Moon and Sun, Leon Golub (author) and Sibyl S. Senters (illustrator) (CreateSpace Independent Publishing Platform, 2016). Illustrated children's book about eclipses. The book, for children maybe 8-12, includes not only a trip to see the eclipse but also to the space-weather center (satellite images) at the Harvard-Smithsonian Center for Astrophysics (called only an Observatory) and a chance for kids to figure out that the Moon goes around the Earth and the Earth/Moon go around the Sun.

55. The Adventures of TinTin: Prisoners of the Sun, Hergé (Little, Brown Books for Young Readers, 1949). Graphic novel.

56. Jordan and the Solar Eclipse, Cara Mayo and Jacqui Fenner, https://www.createspace.com/7113277 (2017). Story of a middle-school girl who is dragged out of bed to see a total solar eclipse.

\section{BOOKS ON ECLIPSE HISTORY AND OBSERVATION}

This year has seen several excellent books for general readers about eclipses, including why it is exciting for the public to see them and what science has been done at past total eclipses.

\section{A. Recent books with extensive discussions of observing eclipses}

57. American Eclipse: A Nation's Epic Race to Catch the Shadow of the Moon and Win the Glory of the World, David Baron (W. W. Norton/Liveright, New York, June, 2017). 
58. Sun Moon Earth: The History of Solar Eclipses from Omens of Doom to Einstein and Exoplanets, Tyler Nordgren (Perseus Books, New York, 2016).

59. Being in the Shadow: Stories of the First Time Total Eclipse Experience, Kate Russo (Being in the Shadow, June 2017). Available at: www.beingintheshadow.com.

60. In the Shadow of the Moon: The Science, Magic, and Mystery of Solar Eclipses, Anthony Aveni (Yale U.P., New Haven, 2017).

61. Eclipse: Journeys to the Dark Side of the Moon, Frank Close (Oxford U.P., New York, 2017).

62. Mask of the Sun: The Science, History and Forgotten Lore of Eclipses, John Dvorak (Pegasus Books, New York, 2017). References 57 and 60-62 are reviewed in "An all-American eclipse," Jay M. Pasachoff, Nature 545, 409 (2017).

\section{B. Other recent eclipse books}

63. Totality: The Great American Eclipses of 2017 and 2024, Mark Littmann and Fred Espenak (Oxford U.P., New York, 2017).

64. Your Guide to the 2017 Total Solar Eclipse, Michael Bakich (Springer International Publishing, 2016). An excellent guide for first time eclipse observers. In addition, the author has a podcast at: https://itunes.apple.com/us/podcast/ 2017-total-solar-eclipse-podcast/id968037305? $\mathrm{mt}=2$.

65. Eclipse Nuts, Bill Kramer (https://www.eclipse-chasers. $\mathrm{com} / \mathrm{html} /$ cartoons.shtml). Eclipse cartoons from the proprietor of http://eclipse-chasers.com.

66. Total Solar Eclipse 2017: Your Guide to the Next US Eclipse, Marc Nussbaum (Audible Rush Learning, 2016).

67. The Solar Eclipse 2017: Where and How to Best View It, Wolfgang Held (Floris Books, 2015).

68. Eclipses Illustrated: Book 1-The Eclipse Experience: A Visual Approach to Understanding Eclipses of the Sun and Moon, Jay Ryan (Amazon Digital Services LLC, Kindle Edition, 2016).

69. Eclipses Illustrated: Book 2-Eclipses and the Orbit of the Moon: A Visual Approach to Understanding Eclipses of the Sun and Moon, Jay Ryan (Amazon Digital Services LLC, Kindle Edition, 2017).

70. America's First Great Eclipse: How Scientists, Tourists, and the Rocky Mountain Eclipse of 1878 Changed Astronomy Forever, Steve Ruskin (Kindle Edition, 2017).

C. Older books on observing eclipses

71. Totality: The Total Solar Eclipse of 2012 in Far North Queensland, Kate Russo (Writers \& Ebooks, Sydney, 2013).

72. Total Addiction: The Life of an Eclipse Chaser, Kate Russo (Springer, 2012).

73. Observe Eclipses! Second Edition, Mike Reynolds and Richard A. Sweetsir (Astronomical League, 1995).

74. Guide to Eclipses, Transits and Occultations, David Levy (Cambridge U.P., 2010).

75. Glorious Eclipses: Their Present, Past, and Future, Serge Brunier and Jean-Pierre Luminet (Cambridge U.P., 2000).

\section{FIELD GUIDES}

76. A Field Guide to the Stars and Planets, Fourth, Updated Edition, The Peterson Field Guide Series, Jay Pasachoff (Houghton Mifflin Harcourt, 2016, 14th printing). 24 pages about this eclipse and other eclipses.

77. Peterson First Guide to Astronomy, Second Edition, Peterson First Guide Series, Jay Pasachoff (Houghton Mifflin Harcourt, 2014).

78. Total Solar Eclipses and How to Observe them, Martin Mobberley (Springer, 2007).

\section{HISTORIC ECLIPSE OBSERVATIONS}

A. Eclipse history and expeditions

79. Eclipses, Transits, and Comets of the Nineteenth Century: How America's Perception of the Skies Changed, Stella Cottam and Wayne Orchiston (Springer, 2016). Book review by Jay Pasachoff: Journal of Astronomical History and Heritage, 18, \#1, March/April, 112. http://adsabs.harvard.edu/abs/ 2015JAHH...18..112P.

80. Empire and the Sun: Victorian Solar Eclipse Expeditions, Alex Pang (Stanford U.P., 2002).

81. American Eclipse: Thomas Edison and the Celestial Event that Illuminated a Nation, David Baron (W. W. Norton, 2017).

82. Total Eclipses: Science, Observations, Myths, and Legends, Pierre Guillemier and Serge Koutchmy (Springer Praxis Books, 1999). Translated from the French: Eclipses Totales: Histoire, Découertes, Observations (Paris, Masson, 1998).

83. Racing the Moon's Shadow with Concorde 001, Pierre Léna (Springer, 2015). Translation of Concorde 001 et L'ombre de la Lune (Cham, Switzerland) by Stephen Lyle.

84. Harlan's Globetrotters: The Story of An Eclipse, David S. Evans and Karen I. Winget (Xlibris.com, 2005). About the expedition to Africa to test relativity in 1973 with the Eddington experiment. The title refers to Prof. Harlan Smith of the University of Texas, with reference to the Harlem Globetrotters basketball-humor team.

85. Eclipse: The Celestial Phenomenon that Changed the Course of History, Duncan Steele (Joseph Henry Press, 2001).

\section{B. Historic eclipse books}

86. Chasing Eclipses: The Total Solar Eclipses of 1905, 1914, 1925, Rebecca R. Joslin (Walton Advertising \& Printing Co., 1929).

87. Total Eclipses of the Sun, Mabel Loomis Todd (Boston, Roberts Brothers, 1894).

88. Eclipses of the Sun, Fifth Edition, Samuel Alfred Mitchell (reprinted 1969, Greenwood Press; Columbia U.P., 1951).

\section{Halley eclipse map (1715/1724)}

The first map that showed the oval of the umbra along the path of totality across Earth's surface. 
89. "Tri-centennial of a historic eclipse and map," Michael Zeiler (GreatAmericanEclipse.com, 2015). https://www. greatamericaneclipse.com/blog/2015/5/2/tri-centennial-ofa-historic-eclipse-map. Website with description and images of Halley's eclipse map.

90. "Halley and his maps of the total eclipses of 1715 and 1724," Jay M. Pasachoff, Astronomy \& Geophysics (Royal Astronomical Society) 40, 2.18-2.21 (April 1999).

91. "Halley as an eclipse pioneer: His maps and observations of the total solar eclipses of 1715 and 1724," Jay M. Pasachoff, Journal of Astronomical History and Heritage 2(1), 39-54 (June 1999).

92. "Halley et ses cartes d'éclipses totales de 1715 et 1724 ," Jay M. Pasachoff, Ciel et Terre 115, mars-avril, 51-56 (1999). In French.

\section{Other eclipse books}

93. Celestial Shadows: Eclipses, Transits, and Occultations, John Westfall and William Sheehan (Springer, 2015). (I)

94. Total Solar Eclipses and How to Observe Them, Astronomers' Observing Guides, Martin Mobberley (Springer, 2007)

95. The Cambridge Eclipse Photography Guide, Jay M. Pasachoff and Michael Covington (Cambridge U.P., 1993). Many sections on observing and photographing eclipses that are still relevant even in a digital age.

96. Eclipse!: The What, Where, When, Why, and How Guide to Watching Solar and Lunar Eclipses, Philip S. Harrington (John Wiley, 1997).

97. Total Eclipses of the Sun, Jack B. Zirker (republished by Princeton U.P.; paperback 2014 and hardback 2016; 1981, 1991, 1995). (I)

98. Le manuel des éclipses, Institut de Mécanique Céleste et de Calcul des Éphémérides, Observatoire de Paris (EDP Sciences, 2005). In French.

99. Eclipse, Bryan Brewer (Earth View, Seattle; 1978).

\section{E. Eclipse canons}

100. Thousand Year Canon of Solar Eclipses, 1501 to 2500, Fred Espenak (Astropixels Publishing, 2014). http://astropixels.com. Color and b/w editions. (A)

101. Five Millennium Canon of Solar Eclipses: -1999 to +3000 (2000 BCE to $3000 \mathrm{CE}$ ), Fred Espenak and Jean Meeus, NASA/TP-2006-214141. (A)

102. Fifty Year Canon of Solar Eclipses: 1986-2035, Fred Espenak, NASA Reference Publication 1178 (Revised July 1987). (A)

103. UK Solar Eclipses from Year 1 (an anthology of 3,000 years of solar eclipses), Sheridan Williams (Clock Tower Press, 1996); UK Solar Eclipses from Year 1 to 3,000, Second Edition (Clock Tower Press, 1999). http://www.shindles.co.uk/book/.

104. Eclipse 2005-2017: A Handbook of Solar and Lunar Eclipses and Other Rare Astronomical Events, Wolfgang Held (Floris Books, 2005).

\section{F. Historical eclipses and the Earth's rotation}

Earth's rotation is not quite constant, as glaciers melt or move around and the mass otherwise redistributes. Observations of totality from thousands of years ago can be used to graph variations in so-called $\Delta \mathrm{T}$, the deviations in time from the currently used value, as a function of date.

105. Historical Eclipses and Earth's Rotation, Richard Stephenson (Cambridge U.P., 1997). Updated in 2003 and reprinted in paperback in 2008.

106. "Historical eclipses and Earth's rotation," F. R. Stephenson, Reviews in Astronomy and Geophysics 44(2): 2.22-2.27 (2003).

107. "Measurement of the Earth's rotation: $720 \mathrm{BC}$ to $\mathrm{AD}$ 2015," F. R. Stephenson, L. V. Morrison, C. Y. Hohenkerk, Proc. R. Soc. A 472: 20160404 (2016).

108. "Earth's spin is slowing at a rate of 1.8 milliseconds per century," Deborah Netburn, Los Angeles Times, December 7, 2016. http://www.latimes.com/science/ sciencenow/la-sci-sn-earth-longer-days-20161205-story. html. News account of Ref. 107.

109. Chasing Shadows: Mathematics, Astronomy, and the Early History of Eclipse Reckoning, Clemency Montelle (The Johns Hopkins U.P., 2011). Opening quotation: "Well, after this, said Socrates, when I was worn out with my physical investigations, it occurred to me that I must guard against the same sort of risk which people run when they watch and study an eclipse of the sun; they really do sometimes injure their eyes, unless they study its reflection in water or some other medium. I conceived of something like this happening to myself, and I was afraid that by observing objects with my eyes and trying to comprehend them with each of my other senses I might blind my soul altogether. So I decided that I must have recourse to theories, and use them in trying to discover the truth about things." Plato, Phaeda 99b-c; ed. Hamilton

110. Stonehenge Watch, with a scale model of Stonehenge inside this plastic pocket watch, "guaranteed to tell time for 5000 years." Stonehenge was [probably] used to predict eclipses, too. http://www.Stonehengewatch.com or http://www.PeterPayack.info. Fifth Millennial Anniversary Edition, 2017.

\section{SOLAR SCIENCE}

A. Books

111. The Sun: Our Star, Robert W. Noyes (Harvard U.P., 1982). (I)

112. The Sun, Second Edition, Donald H. Menzel (Harvard U. P., 1959). (I)

113. Nearest Star: The Exciting Science of Our Sun, Second Edition, Leon Golub and Jay M. Pasachoff (Cambridge U.P., 2014). Chapter 5, pp. 128-168, is about eclipses. (I)

114. The Complete Idiot's Guide to the Sun, Jay $M$. Pasachoff (Alpha, New York, 2003). A personal, lighthearted survey, including anecdotes. The book is available as a free download at: www.williams.edu/ astronomy/sun. 
115. The Sun, Leon Golub and Jay M. Pasachoff (University of Chicago Press, June 2017; Reaktion Press, UK, for the Science Museum (London), 2017).

\section{OTHER ONLINE RESOURCES}

\section{A. Collections of eclipse videos}

116. Royalty-free Eclipse Images and Video (compiled by the American Astronomical Society): https://eclipse.aas. org/resources/images-videos. Ref. [10].

117. Educational Videos about Solar Eclipses (scroll to the bottom of the page): https://eclipse.aas.org/resources/ educational-materials.

118. NASA Eclipse Videos and Animations: https://eclipse 2017.nasa.gov/videos-images.

119. Database of Eclipse Videos by David Makepeace (documentaries and dramatic films): http://eclipseguy.com/ eclipse-film-database/.

120. Instructional Eclipse Videos from the Exploratorium: http://www.exploratorium.edu/eclipse.

\section{B. Videos about the Sun that feature eclipses}

121. Colors and Motions of the Sun, Second Edition, Jay Pasachoff (2013). Duration about $8 \mathrm{~min}$. http://solarcenter.stanford.edu/cmos/. Target grades 9 to 12 .

122. Colors of the Sun, Stanford Solar Center (2014). Available at: http://solar-center.stanford.edu/colors/. Target audience of middle school.

123. Solar Eclipse 2009 HDR Time Lapse Fisheye for Planetarium Dome-Ansibletech/Williams Expedition, Aram Friedman (2009). Video available at: http:// www.ansibletech.com/solareclipse2009.html. The 2009 eclipse wide-angle video.

\section{Selected videos about eclipses}

(see Sec. VII A for more)

124. "Eclipse: Countdown to Totality," Beau Hartweg (2016). Available at: https://www.youtube.com/ watch? $\mathrm{v}=$ PdjI789nqno Planetarium show created in Worldwide Telescope to educate audiences about the 2017 total solar eclipse.

125. "Solar Eclipse Movie Archive Channel," Mike Kentrianakis. Available at: http://www.youtube.com/ user/mkentrianakis. YouTube Channel dedicated to digitized solar eclipse movies.

126. "Storm Worlds: Cosmic Fire," National Geographic Documentary (2010). http://youtu.be/zQbRfOfnIHI. Scenes from the documentary of the Solar Eclipse of July 22, 2009 in China are shown.

127. "Solar Eclipse 2010 July 11, Easter Island," Mark Bender, Director; National Geographic Documentary (2010). Available in five parts on YouTube. Part 1: http://youtu.be/Vc0UpnGaMvg; Part 2: http://youtu.be/ fEF0b3PYITs; Part 3: http://youtu.be/D2jeuE33Avg; Part 4: http://youtu.be/qJj0zFEqPXE; Part 5: http://youtu. be/4kNB9G89dxY.

128. "Solar Eclipse 1973 June 30, Mauritania," National Geographic Documentary (1973). Available in two parts on YouTube. Part 1: http://youtu.be/juImmdasMSY; Part 2: http://youtu.be/Z6JfBAALRQQ.

129. "Solar Eclipse 1973 June 30, Kenya," National Geographic Documentary (1973). Available in two parts on YouTube. Part 1: http://youtu.be/W9BmDtCdKi8; Part 2: http://youtu.be/W8ujcpKiWMQ. In Part 2 the diamond ring effect is shown, followed by final pretotality, and the second diamond ring.

\section{Podcasts about eclipses}

130. "Eclipse 2017 Podcasts," Michael Bakich, http://m-bakich. podomatic.com/. From one of the editors of Astronomy magazine.

131. "NASA Edge: Eclipse 2017 Preview," https://www.nasa. gov/nasa-edge/1005-solar-eclipse-2017-preview-show.

132. "The 2017 Eclipse Crossroads of the World," Bob Baer and Harry Treece, http://www.stitcher.com/podcast/ seattle-astronomy-podcast/e/44171107. About eclipse observation plans in Southern Illinois.

133. "Academic Minute: Eclipses of 2015 and 2017," Jay M. Pasachoff (2015). http://academicminute.org/2015/ 03/jay-pasachoff-williams-college-todays-total-solareclipse/. An Academic Minute is scheduled on eclipse day of 2017.

134. 365 Days of Astronomy: Podcasts, Videocasts, and More. http://365daysofastronomy.org and https://cosmoquest. org/x/365daysofastronomy/. Search within for desired content. For example, all of Jay Pasachoff's podcasts are available at: https://cosmoquest.org/x/365daysofastronomy/author/jaypasachoff/ and will also include a podcast on the 2017 total eclipse. A few examples are below.

135. "The Indonesian Total Solar Eclipse of $8 / 9$ March 2016," Jay M. Pasachoff, 365daysofastronomy.com, March 6, 2016. http://cosmoquest.org/x/365daysofastronomy/2016/03/06/mar-6th-the-indonesian-totalsolar-eclipse-of-89-march-2016/.

136. "The Minus-first Anniversary of the Great American Eclipse," Jay M. Pasachoff, 365daysofastronomy.com, August 21, 2016. http://cosmoquest.org/x/365daysofastronomy/2016/08/21/aug-21st-the-minus-first-anniversary-of-the-great-american-eclipse/.

137. "2017 Annular Eclipse and a post-Pluto Spacecraft Mission," Jay M. Pasachoff, 365daysofastronomy.org, February 26, 2017. https://cosmoquest.org/x/365daysofastronomy/2017/02/26/feb-26th-the-2017-annular-eclipseand-a-post-pluto-spacecraft-mission/.

\section{E. Solar conditions}

138. Solar Influences Data Analysis Center, Royal Observatory of Belgium. http://sidc.oma.be/silso. Sunspot-cycle information with graphs updated each month.

139. Solar Monitor Website. http://solarmonitor.org. Daily images from a variety of solar telescopes on the ground and in space.

140. Space Weather Website. http://spaceweather.com. Space weather and daily sunspot images.

141. DIY Sun Science Website. http://www.lawrencehallofscience.org/do_science_now/science_apps_and_ activities/diy_sun_science. NASA sponsored website from the Lawrence Hall of Science, University of California, Berkeley. 


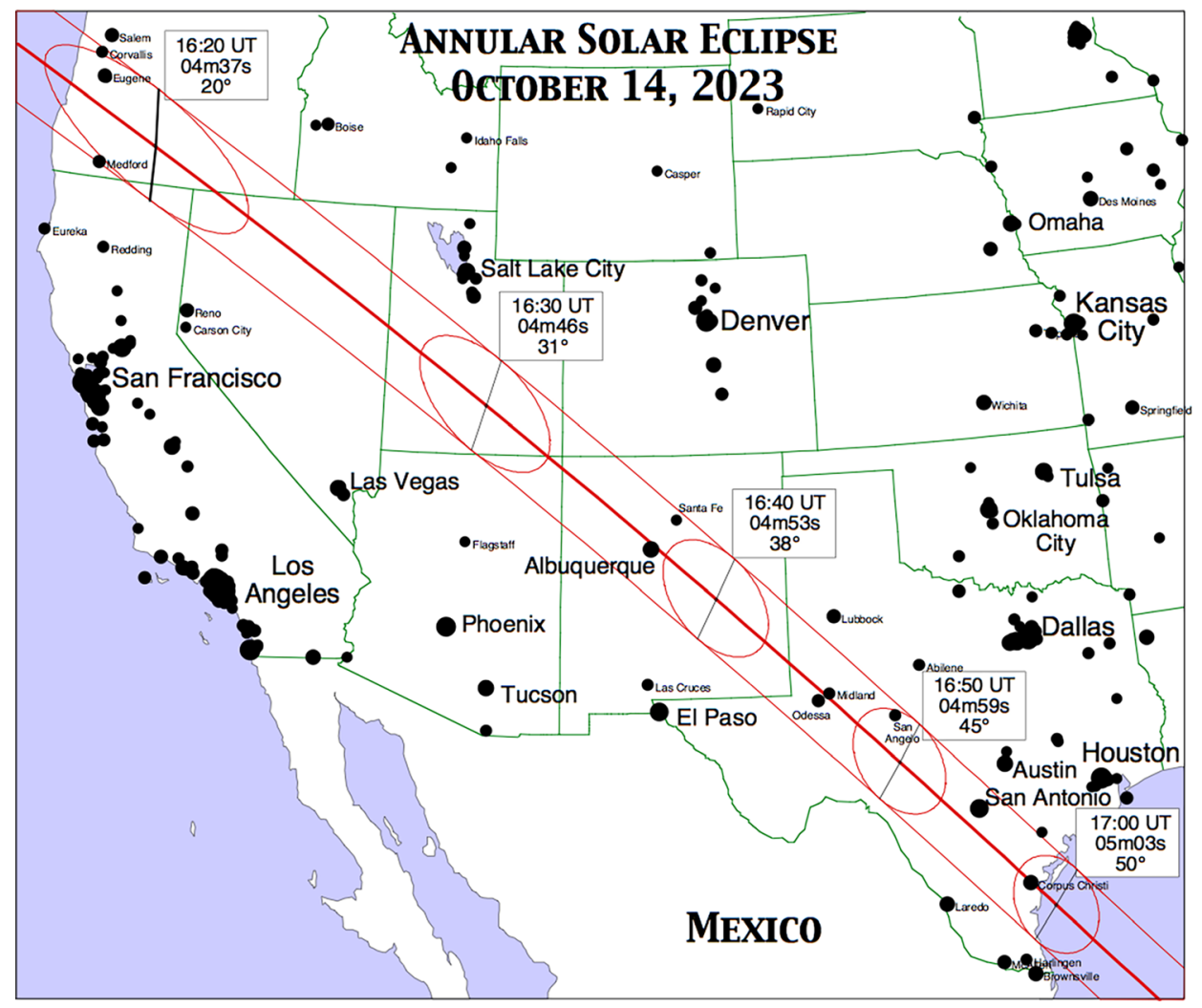

Fig. 5. The visibility of the October 14, 2023, annular eclipse. For those viewing only partial phases, those views will be the same as those gotten outside totality of a total solar eclipse. (Map and eclipse data courtesy of Fred Espenak, "http://www.eclipsewise.com/"www.EclipseWise.com).

142. NASA Space Weather Mobile Media Viewer. https:// sunearthday.nasa.gov/spaceweather/. Website from NASA showing current images of the Sun and other space weather phenomena.

\section{F. Maps for the 2023 and 2024 American eclipses}

American, Canadian, and Mexican viewers of partial phases of the 2017 eclipse will also be able to view the partial phases of the October 14, 2023, annular solar eclipse
(Fig. 5) and of the April 8, 2024, total solar eclipse (Fig. 3). The paths of totality of fifty years of future total solar eclipses are also shown (Fig. 6).

143. Google map by Xavier Jubier for the October 14, 2023, annular solar eclipse. Viewers can zoom in and click anywhere to get local circumstances. See Fig. 5. http:// xjubier.free.fr/en/site_pages/solar_eclipses/xSE_Google Map3.php?Ecl $=+20231014 \& A c c=2 \& U m b=1 \& \mathrm{Lmt}=1$ $\& \mathrm{Mag}=1 \& \mathrm{Max}=1 \& \mathrm{Map}=\mathrm{ROADMAP}$

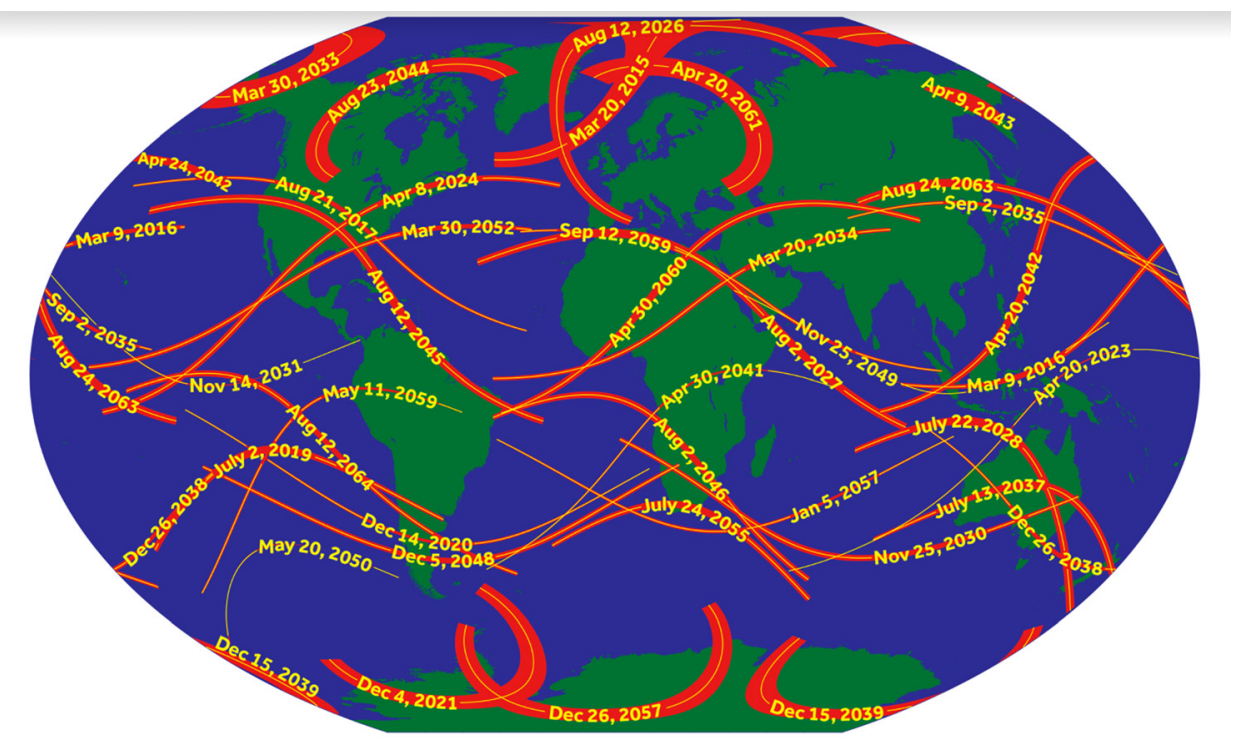

Fig. 6. Total solar eclipses from 2015 to 2065. (Courtesy of Michael Zeiler, GreatAmericanEclipse.com). 
144. Google map by Xavier Jubier for the April 8, 2024, total solar eclipse. Viewers can zoom in and click anywhere to get local circumstances. See Fig. 3. http://xjubier.free. fr/en/site_pages/solar_eclipses/xSE_GoogleMap3.php? $\mathrm{Ecl}=+20240408 \& \mathrm{Acc}=2 \& \mathrm{Umb}=1 \& \mathrm{Lmt}=1 \& \mathrm{Mag}=1$ $\&$ Max $=1 \&$ Map $=$ ROADMAP

145. 2024 map for the 2024 total solar eclipse at the Great American Eclipse site by cartographer Michael Zeiler https://www.greatamericaneclipse.com/april-8-2024/.

146. 2024 Google map by Fred Espenak, who formerly made NASA's eclipse site from the Goddard Space Flight Center: https://eclipse.gsfc.nasa.gov/SEgoogle/ SEgoogle2001/SE2024Apr08Tgoogle.html.

\section{ACKNOWLEDGMENTS}

The research of J.M.P., his students, and his research colleagues at the 2017 eclipse is supported by grants from the Solar Terrestrial Program of the Atmospheric and Geospace Sciences of the National Science Foundation and from the Committee for Research and Exploration of the National Geographic Society. Additional support has been received for students from the Sigma Xi (the Scientific Research Honor Society), the Clare Booth Luce Foundation, and the NASA Massachusetts Space Grant Consortium, as well as from the Freeman Foote Expedition Fund, the Brandi Fund, and other funds from Williams College.

The American Journal of Physics (AJP) invites you to submit papers for a special theme issue focused on Energy as a subtle Concept.

The teaching of energy is generally considered by physicists to be an important core concept to understand the material world. Educators at all levels teach basic concepts of energy to students; however, many of the core energy ideas taught to students are not consistent within the physics community, or between physics and other disciplines like life science and chemistry. Energy is sometimes regarded solely as an accounting principle, a calculated quantity representing an abstract idea, not a physical construct. Unlike matter, it is difficult for students to construct a physical representation of energy, and they often struggle to understand energy as a conserved quantity. As Richard Feynman noted in a speech to teachers, "Energy is a very subtle concept. It is very, very difficult to get right."

While there are over 200 Journals devoted in some form to energy research, there are few instances of entire journals devoted to the learning and understanding of energy at the undergraduate level. We wish to publish papers from introductory to advanced levels that describe advances in fundamental understanding of energy and in the teaching and learning of energy at the post-secondary level. Examples of topics that would fit well in this collection are as follows:

- Discoveries, technologies, and experiments that excite students and emphasize energy conservation, transformation, transfer, harvesting, or degradation;

- Research on how students, teachers, and scientists understand and represent energy ideas and how to promote a deeper understanding of key energy ideas;

- Development of energy focused courses;

- Teaching of energy concepts within specific courses (including interdisciplinary courses); for example, development of new laboratories, visualizations, and curricula

- Critical reflection on what energy related ideas and representations are most useful for different cohorts of students.

This theme issue will be published in the spring of 2018. The deadline for the submission of articles is August 13, 2017; papers submitted after this date will continue to receive consideration if time permits. Manuscripts should be submitted in the usual way with your interest in being considered for the theme issue specified in a cover letter. Contact the guest editors, Nancy Ruzycki (nruzycki@mse.ufl.edu) or Dawn Meredith (dawn.meredith@unh.edu) with any questions, comments, or suggestions about the AJP theme issue.

Energy as a Subtle Concept: Research and Teaching of Energy will be the topic of the next Gordon Research Conference on Physics Research and Education to be held June 10-15, 2017 at Bryant University, Smithfield, RI. The co-chairs are Nancy Ruzycki, University of Florida, and Dawn C. Meredith, University of New Hampshire, Vice-Chairs are Shane Larson, Northwestern University, and Sean Robinson, Massachusetts Institute of Technology. 